\title{
HIV/AIDS Antenatal Consultations as Regulative Discourse: The Case of Malawi
}

\author{
Rachel Chimbwete-Phiri, University of Warwick \\ Malcolm N. MacDonald, University of Warwick
}

\section{Introduction}

Applied linguistics is commonly regarded as the investigation of the ways in which language is used in everyday life and in institutional settings such as education and health, often with a view to improving professional practice. However, to date, the scope of its engagement with health communication has mostly focused on relatively well-resourced contexts in the global North, while less well-resourced contexts in the global South have remained relatively underreported. In particular, educational and counselling sessions on HIV/AIDS in African countries have been largely ignored, especially in remote areas such as rural Malawi. Across Malawi, HIV/AIDS has for a long time been the most challenging health issue. Out of a population of about 17 million, 979,482 people are estimated to be infected with the virus (PEPFAR 2017). Although various health care interventions have been introduced to reduce new infections and manage the pandemic with antiretroviral drugs, the adult HIV prevalence is currently $10.6 \%$. In spite of different health care interventions, public health

\section{How to cite this book chapter:}

Chimbwete-Phiri, R. and MacDonald, M.N. 2019. HIV/AIDS Antenatal Consultations as Regulative Discourse: The Case of Malawi. In: Wright, C., Harvey, L. and Simpson, J. (eds.) Voices and Practices in Applied Linguistics: Diversifying a Discipline, pp. 143160. York: White Rose University Press. DOI: https://doi.org/10.22599/BAAL1.i. Licence: CC BY-NC 4.0 
services relating to HIV/AIDS in Malawi are struggling with less than adequate adherence by women and infants to all the recommendations for the prevention of mother to child transmission (PMTCT) of the virus. Reasons for low adherence include economic status, lack of independence in decision-making in matters of health and sexual practice and lack of male involvement in antenatal HIV/AIDS consultations (Haas et al. 2016; Tenthani et al. 2014; Keehn \& Karfakis 2014). This chapter is taken from a larger study which explores routine group counselling sessions provided to pregnant women at antenatal clinics as part of a PMTCT programme (Chimbwete-Phiri 2019).

In presenting part of this work here, we hope to extend the scope of applied linguistics' engagement with health communication by investigating the discursive practices of health professionals and pregnant women in rural Malawi, who are engaged in HIV/AIDS group counselling sessions. However, this chapter will also diversify approaches towards applied linguistics by combining a more conventional sociolinguistic analysis of health communication with a more critical sociological theory, originally developed in the field of education (Bernstein 1990, 1996, 2000), in order to better understand the relationship between the professional discourse that takes place during HIV/AIDS counselling in Malawi and the institutional context in which it is located. In so doing, we will demonstrate how applied linguistics is able to reveal the relations between the discourse that takes place between health professionals and pregnant women and the institutional context in which it is located and how these can have implications for the improvement of communication within HIV/ AIDS counselling. By analysing the discourse of the marginalised and vulnerable in HIV/AIDS discourse in rural Malawi and discussing its implications for the improvement of communication, we hope to contribute to healthcare interventions for better compliance with HIV/AIDS treatment.

\section{Pedagogic discourse in the clinic}

Pedagogic discourse is a theory developed by Basil Bernstein (1990, 1996, 2000) which describes the principles that govern agency and social relations within the field of education. Although Bernstein's theory of pedagogic discourse emerged from the field of education, it also has the potential to describe the production, transmission and reproduction of knowledge in other institutional contexts, including that of the clinic or health centre (MacDonald 2002). From the purview of pedagogic discourse, the health centre is viewed as a context within which medical knowledge is reproduced. This reproduction of medical knowledge is realised as medical discourse is delocated from the 'context of production' (the university and laboratory), transmitted via 'the context of recontextualisation' (medical school, public broadcasting service, publishing house) and relocated in the 'context of reproduction,' the clinic, 
health centre (MacDonald 2002, after Bernstein 1996) or, in this case, the counselling session.

Bernstein's critical educational sociology enables an applied linguistics approach which describes the language and discourse within a particular institutional setting to be related to structural mechanisms of social control. A distinction is made between two types of discourse which are embedded in the transmission and acquisition of medical knowledge: 'regulative discourse' and 'instructional discourse.' In Bernstein's terms, the framing of pedagogic discourse describes the rules that govern the relations of participants across the social hierarchy (regulative discourse) and rules that govern relations between different types of knowledge (instructional discourse). This means that selection of knowledge within the classroom or clinic has the potential to influence relations between the social agents at the micro level of the discourse (Bernstein 1996; Buzzelli \& Johnston 2001). Access to, and facility in, different knowledges and discourses (e.g., 'authorised' or 'local') therefore become determinants of power asymmetries that are constituted between participants in institutional talk. For its part, applied linguistics can provide a micro-analysis of conversational interaction in order to better understand the symbolic control which takes place at the macro-level of institution and society, since within the fields of both education and health are embedded regulative discourses of social order and conduct that operate beyond the classroom or clinic (Buzzelli \& Johnston 2001). For example, it has been reported that as students learn reasoning skills they also internalise what it means to be 'morally compliant' citizens (Love 2000: 422). In a similar fashion, medical consultations are intertwined with pedagogical processes as medical knowledge is imparted to patients (Montgomery et al. 2006; Hult et al. 2009).

This regulative function also extends to health promotion programmes charged with imparting knowledge ostensibly to 'empower' HIV/AIDS patients. Paradoxically, these have been also described as creating subjectivities in individuals which are linked to promotion of neo-liberal ideologies of social reform of medicine (Finn \& Sarangi 2010). For example, Jane Mulderrig has recently conceptualised pedagogic discourse in the UK anti-obesity campaign Nudge as a form of 'biopedagogy' whereby medical knowledge is recontextualised with 'normative, socially regulative, and reproductive functions' (2017: 3). Thus, regulative discourse is employed in our analysis to conceptualise not only the power relations between health professionals and the women that are constituted in the HIV/AIDS counselling sessions, but also the modalities of control that are exercised through the legitimisation and delegitimisation of distinct systems of knowledge relating to women's health and sexual practices in the home. Different types of knowledge have been shown to include local and nonspecialised knowledge which is derived from people's everyday practices (MacDonald et al. 2009; van Dijk 2002), local knowledge which is outside technical and official knowledge (Higgins \& Norton 2010) and experiential knowledge. 


\section{Methodology}

Our data are drawn from over 20 hours of audio recordings of counselling and health educational sessions held by health professionals with various groups of pregnant women attending an antenatal clinic in a rural community hospital in Malawi. The chapter is part of a larger sociolinguistic study involving audio recordings of interaction, observations, interviews with the participants and document analysis. The transcription conventions utilised in the audio data are presented in Appendix A.

As with most of the studies in health communication reported in the previous section, analysis of our empirical data is carried out using techniques of discourse analysis. Discourse analysis is typically used in applied linguistics to reveal generally how power relations are negotiated in talk (Sarangi \& Roberts 1999 ) and the ways in which language is linked to reproduction of ideologies, power relations and medical realities (Lupton 1992). However, in this chapter our exploration of HIV counselling will elucidate the power relations in the counselling sessions more specifically by focusing on their regulative function (after Bernstein 1990, 1996, 2000). The discourse of HIV/AIDS realises a range of social practices related to everyday life, such as taking care of the self and family, relating to one's spouse and following expert advice. These practices also entail the social relations surrounding the discourse (e.g., husband and wife, mother and child, mother and health expert) (see van Leeuwen 2008). Our analysis will therefore not only extend the scope of applied linguistics contextually, by investigating how the experiences of the women clients affected by the HIV/AIDS pandemic are realised in the talk of the counselling sessions, but also conceptually, by linking the micro-level details of interaction with the macro-level structures of social and institutional practices. Our empirical analysis therefore specifically addresses the following two questions:

- How is regulative discourse realised in HIV/AIDS counselling sessions in rural Malawi?

- What implications does this regulative discourse have for the clients' agency in their everyday practices?

Ethical consent for the larger study was granted by the University of Warwick and the National Committee on Research in the Social Science and Humanities (NCRSSH) in Malawi. Informed consent was also obtained from all participating health professionals and clients.

\section{Analysis}

Antenatal counselling sessions ostensibly enhance knowledge of HIV/AIDS, encourage HIV testing and enable the women to make informed decisions 
about their health. On the upside, Chimbwete-Phiri (2019) and ChimbwetePhiri \& Schnurr (forthcoming) have demonstrated that health professionals use discourse strategies that facilitate negotiation of knowledge and demonstrate their aims to collaborate with the women to achieve the aims of the consultations. However, in further diversifying applied linguistics approaches to health consultations, this analysis focuses on the regulative aspects of antenatal consultations, not least because of contradictions that the different discourse strategies demonstrate. Within the constraints of this chapter, we go on to analyse three extracts which exemplify the interaction that takes place between the health professionals (counsellors) and the pregnant women to illuminate the discursive practices employed by the participants. In the following sections of analysis we particularly focus on the 'selection, sequence, pacing and criteria of the knowledge' (Bernstein 1996: 28) that take place within HIV/AIDS counselling sessions in Malawi.

\section{Relationship between types of knowledge}

The examples below demonstrate how the health professionals utilise a question-and-answer format to facilitate the reproduction of medical knowledge among the women, thereby revealing a relationship across different types of knowledge. Examples 1 and 2 below are extracts from a talk by a female health professional (HP1) talking to a group of 14 pregnant women (W represents several or all women speaking at the same time, while W1, W2, W3 etc. refer to individual women in each example). At this stage in the exchanges (examples 1 and 2) they are talking about specific ways of preventing the transmission of HIV from mother to child. The extracts are the clients' responses to HP1's question: 'The mother is diagnosed with HIV (.) how can she protect her child from contracting HIV?'

\section{Example 1}

$1 \quad \mathrm{HP1}$ Mayi wapezeka kuti ali ndi kachilombo ka HIV (.)

HP1: The mother is diagnosed with HIV (.)

2 angamuteteze bwanji mwana wake (.) how can she protect her child (.) kuti asatenge HIV? (6) from contracting HIV? (6)

4 W1: Apite kuchipatala akayezetse magazi

W1: She should go to the hospital for a blood test

5 HP1: Choyambirira, apite ku chipatala akayezetse

HP1: The first thing, she should go to the hospital to get tested 
7 W: $\quad$ ((Some) $) M m m$

$\mathrm{W}: \quad$ ((Some)) $\mathrm{Mmh}$

8 HP1: Chachiwiri? (.) Ngati wapezeka nako kachilombo?

HP1: The second thing? (.) if she is diagnosed with the virus?

9 W2: Alandire zotsatira ndi [mankhwala amene ampatse]

W2: $\quad$ She should accept the results [and the medicine she receives]

10 W3: Alandire treatment

W3: She should receive the treatment

$11 \mathrm{HP1}$ Alandire treatment (.) ayambe kulandira ma $A R V$ (.)

HP1: She should get treatment (.) she should start receiving ARVs (.) Adzimwa mwadongosolo, Taking the medicine according to the regulations,

14 W: $\quad$ Mmm $>$ according to hospital regulations $<$ right?

W: $\quad \mathrm{Mmh}$

In example 1, HP1 asks the women questions, ostensibly to engage them in the counselling talk, rather than unilaterally presenting information about the anti-retroviral regime (ARV). On the one hand, this strategy appears to really engage the women in contributing answers to the talk (see Chimbwete-Phiri 2019); however, it is the way in which the women make this contribution that is of particular interest here. As the women respond to the question about how they should avoid infecting their children with HIV, HP1 uses repetition to reinforce the women's answers. For example, when W3 responds, 'She should receive the treatment' (line 10), HP1 repeats this answer and adds 'she should start receiving ARVs (.) taking the medicine according to the regulations' (line 11). Here, her repetition and additions function to affirm the correctness of the answers given by the women, ratify them and thereby instruct the women. In this exchange, HP1 asserts a degree of certainty regarding what knowledge is legitimate and what is not. As she repeats the women's responses (lines 5-6, 11-13) she also appears to evaluate the information as correct, hence reinforcing authorised medical knowledge. This format realises the regulative function of the discourse and facilitates the shaping of the text into a form that is acceptable in line with legitimate medical knowledge.

The knowledge about the ARV regime that is being reaffirmed in example 1 is not something that originated in the women's personal experience. Rather, the participants are being required within the counselling session to recall clinical information that has been produced in one context and is recontextualised into the current setting, in the process compromising the extent of the women's agency as social actors. HP1's question opens with a neutral referent, 'pregnant 
woman infected with HIV,' leading to the use of the third-person pronoun 'she' rather than a direct referent to the women, such as the use of the second-person pronoun 'you' (lines 1-3). HP1's formulation of a generic and distanced subject 'the pregnant woman' rather than directly addressing the women with 'you' demonstrates a form of passivation of the women into the role of benefactors, rather than positioning them as social actors with agency (van Leeuwen 2008). For their part, the women adopt the same linguistic form, answering with the same impersonal referent 'she', thus colluding in their own construction as passive subjects. Moreover, use of the modal auxiliary 'should' serves to reinforce the regulative power that the medical institution exercises over the women (as 'clients', through its agent (the health professional). The medical institution (the hospital) is also represented as being the body which conveys authority through statements such as 'according to hospital regulations' (line 13). The woman in question is therefore constructed as a compliant subject, the 'normal citizen,' who conducts herself according to institutional guidelines, while the hospital is constructed as a regulating 'semiotic agent' (Moore 2005: 108) which oversees compliance with the regime whereby the testing, diagnosis and treatment of HIV is carried out.

The element of 'framing' in pedagogic practice is the device that discursively constitutes the criteria for legitimate knowledge. Framing is a means whereby the knowledge which is constructed in the talk is evaluated against a certain baseline of authorised knowledge (Bernstein 1996). HP1, in example 1, demonstrates this principle as she evaluates the women's responses to her questions. As HP1 develops her talk on the basis of the women's responses, she mobilises her professional authority to legitimise what is being talked about. While the women present their answers, thereby colluding in the reproduction of medical knowledge, HP1 enacts her authority by controlling what knowledge is selected for inclusion in the talk. Although HP1 elicits information from the women, classically, the question-and-answer format constructs an asymmetry of roles enabling her to be in control (Walsh 2011). Similar to classroom discourse, the health professional initiates, and the clients respond, before she gives them feedback. This format has long been dubbed 'Initiate, Respond, Feedback' (or 'IRF': Sinclair \& Coulthard 1975; Walsh 2011), but has not hitherto been identified in a context such as this. Through exercising this form of discursive control, the health professional selects what type of knowledge to discuss in this forum, acting as gatekeeper as to what forms of knowledge to incorporate into this medical interaction (Vickers et al. 2012), and directing the talk towards its institutional goals.

However, as can be seen from their responses, the women are already able to safeguard against the transmission of HIV/AIDS. They already appear to have the knowledge, but the forum seems to be where the health professional ratifies their information and appropriates the form of its articulation. This was confirmed when the women indicated elsewhere in their interviews that they already had knowledge about HIV/AIDS prior to the counselling sessions, 
which they had gleaned from community meetings and gatherings, social networks, education talks at the health centre and from mass media promotions. Example 2, a continuation of the talk above, illustrates how HP1's preference for certain forms of knowledge was displayed through her selection of topic. In this extract, HP1 asks about other ways by which a pregnant woman can prevent infecting her child with HIV.

\section{Example 2}

15 W4: Adzikagona ndi abambo modziteteza She should have protected sex with her husband

16 HP1: Adzikagonana ndi abambo pogwiritsa ntchito kondomu?

HP1: She should use a condom when having sex with the husband? mwi:na zikhoza kutheka eti? perhaps it will be possible, right? pogwiritsa ntchito kondomu, eti? by using a condom, right? Komano nanga mimba ibwera- yabwera bwanji But in that case, how can- has she conceived ngati akugwiritsa ntchito kondomu pamenepo, eti? = if they have been using a condom? Right? =

21 W5: =koma mimba ndiya abambo omwewonso

W5: =And the pregnancy is by the same man

22 HP1: $\quad$ Mmm

HP1: $\quad$ Mmh

23 W5: nzovutanso he he he

W5: That is a difficult one heh heh heh =

24 HP1: =Chabwino, chabwino iyoyo ya kondomu mwina tiisiye uko HP1: =okay. Okay, perhaps we should put the condom issue aside tikambebe njira zina (.) Komabe ndizofunikira eti? let us mention other ways (.) However it is important (.) right?

In example 2 one woman (W5) enacts her agency in the talk by giving an unelicited comment in response to the challenge that using protection for pregnant woman raises (lines 21,23). In this case the responses by W4 that she should have protected sex with her husband' is in light of medical recommendation that couples should use condoms when they are both diagnosed with HIV to prevent any increase in the viral load and where one is HIV-negative and the other is HIV-positive (referred to as 'discordant couples'). Two women's responses (W4 and W5) to HP1's question show an example of such a challenge, that is of a pregnant woman who is HIV-positive and is to use condoms with her husband. HP1 expresses doubts to W4's answer but does not address how this could be understood. W5 gives a rejoinder to HP1's statement 
(line 21) which shows an enactment of agency by the women to actively evaluate the information by saying 'that is a difficult one' (line 23). This signals the potential for agency of the woman in the talk, to comment and even interrupt a health professional. However, in line 24 (and the following lines not shown here) HP1 explicitly dismisses the subject when she uses an emphatic 'Okay. Okay [line 25] perhaps we should put the condom issue aside.' Instead, HP1 proceeds to set out the need for married couples to know each other's HIV status (i.e., that in the case of discordant couples it is easy for the woman to contract HIV). She finishes the advice by stating 'or maybe you are sleeping with this man and sleeping with that one, it is very easy for you to contract HIV, and you transmit it to your child very easily.' In this case she does not attempt to gather more information from the women's own experience regarding W5's challenge to condom use.

W5's intervention in this extract realises a counter-discursive position held by one of the clients, that is to present the potential contradictions inherent in relating authorised medical knowledge to experiential and local knowledge. W5, as well as the rest of her group, may potentially have insights into their experiential knowledge related to the subject, that as 'expert patients' (e.g., Sanderson \& Angouri 2013) they may have insights into the challenges that using condoms may pose. Instead, W5's comment and the issue it raises is not discussed as the focus goes back to what 'should' (legitimately) be done to prevent HIV transmission. Thus, W5's contribution is made to appear awkward, as is also seen by her laughter at the end of her sentence (1. 23). While this may serve to mitigate the effects of her utterance privately, this laughter is not echoed by HP1 or anyone else in the group. Thus, by controlling what is raised in the talk, HP1 positions herself as the expert and exercises control of the discussion. This example illustrates the way in which the reproduction of the social asymmetries in this institutional context are reflected 'in what is left unsaid, interrupted, cut-off or de-emphasized' (Waitzkin 1991: 40).

Just as in classroom discourse in which a teacher may engage the students' knowledge but as a teacher is also not only 'an authority' in the topic but also 'in authority' (after Buzzelli \& Johnston 2001: 880), the health professional regulates what is raised in the talk. As demonstrated in examples 1 and 2, HP1 is in control of not only the topics - relating to the ARV regime and the transmission of $\mathrm{HIV}$ - but also how the participants interact at this point, and thereby remains in control of what is legitimate within this context. Eventually HP1 seems to favour didactic talk with question and answers as a strategy that checks the legitimate knowledge as that which is appropriate in this forum (i.e., reinforcing what should be done in line with the hospital regulations). Consequently, the type of knowledge in the discussion and the nature of interaction is regulated as it reverts to the official forms through emphasis on information delivery rather than discussion. In fact, there are no instances when the women presented other preferences as to what is to be discussed, which were accepted as legitimate. This creates a formal hierarchical relation between the health professional as an expert and the women as non-experts. This control may have implications for 
the women's enactment of agency not only in the talk but also in practice, since a 'critical health literacy' is not encouraged in this case (Kreps 2012: 14).

\section{Social relations of the participants}

Depending on the particular health professional, some allowed more agency on the part of the women, and therefore permitted the inclusion of other types of knowledge. In this respect, the framing of pedagogic discourse as regulative can be 'visible' (i.e., explicit) or 'invisible' (i.e., implicit). Thus, the degree of explicitness of pedagogic discourse, in turn, makes the creation of 'pedagogic subjects' relatively visible or invisible (Bernstein 1990: 173; also Love 2000). Commands that create a 'local order' construct explicit regulative discourse, such as when HP1 demands a change of subject by uttering 'let's leave that aside' in example 2, were used on several occasions. This regulative discourse is the practitioners' means of normalising the practices of the medical interaction, as well as normalising the medical knowledge in question. This discourse also reinforces the institutional relationship (e.g., Waitzkin 1991) between the health professionals as experts and the women as non-experts. In the example that follows we demonstrate how the participants in the talk realise power relations institutionally and socially, thus rendering the regulative discourse explicit and 'visible.'

In the lengthy example 3 that follows, a female health professional (HP3) talks to a group of 23 women about the use of condoms for couples who are infected with HIV. Here, HP3 utilises a more collaborative discourse strategy as she asks the women a question which emanates a discussion among them: 'in our homes are we using condoms or we have stopped?' Several women (W2, W3, W4, W5) enact their agency in the talk by actively resisting what HP3 said. Although this question may not be relevant to all the women, their responses indicate that they are not in fact using condoms and narrate the difficulties by giving relatively lengthy responses: about nine lines for W2, and 17 lines for W3. Through such active counter-discourse the women negotiate the practicalities of using a condom (e.g., Stivers 2006), as well as the challenges which they face in following hospital advice. In counterpoint to the orderly IRF format of the previous extracts, several women talk at once and there is a clear involvement on the part of most of the women as they chatter indistinctly and laugh. Here, the women's talk is an example of the contradictions that the women face, their own agency to meet the requirements of the clinic as the regulative institution and the partner who does not comply with 'what the hospital requires of both of you' (1.13).

\section{Example 3}

$1 \quad$ W2: Azibambowa, monga mmene mwanenera kale eti?

W2: these men, as you have already said right? 
'Alibe experience yobwera kudzayezetsa

They do not have the experience of coming here to get tested kuti amve uphungu wabwino ${ }^{\circ}$ and to receive proper counselling ${ }^{\circ}$

Ndizotheka iwe mzimayi

It is possible that you the woman ukutenga zozitetezera zija eti? are getting the protective tools right?

Nde pali azimuna ena amatha kungovara (.) mongokuyerekeza But there are some men who (.) pretend to put it on iweyo ukamakhala udziwona kuti anzanga atani? (.) so that you should think that my partner has what? (.) avala eti? (.) has put it on, right? (.) komano nthawi zina pogwira ntchito paja angathe But during the work he may kuyigwetsera mwina pansi paja (.) drop it on the floor (.) iwe opanda kudziwa kuti chachitika nchani without you being aware of what has happened

((lines omitted as HP3 asks the women what happens when they have sex and asks questions that challenge the women. Laughter and chattering))

12 W3: IYAYI iweyo utha kumuumiriza kuti apange zimenezozo

W3: NO, but you can force him to use it ...

13 komano kuti iye akwaniritse kuti iweyo yachipatala igwire ntchito

But for him to do what the hospital requires of both of you... oro azimayi ambiri kunoko amabwera okha amene even most women come here alone ((omitted some lines as more women join in with laughter))

15 W3: nde ameneyo umutengere chishango (.)

W3: so even if you collect condoms for such a man achivala molongosoka? can he wear it properly?

17 HP3: Inu mmati bwa? Ee inu

HP3: What are you saying? Yes, you.

18 W6: chishangocho amatha kuchiboora panthawi yomwe akuvala... W6: They puncture the condom as they put it on...

((Some lines omitted where HP3 asks the women at what point the man wears the condom and some of the women say the man wears it while they watch and talk about the cunning nature of the men))

19 HP3: Chabwino, chabwino zikatero (.) eti?

HP3: Okay, okay in that case (.) right? 
Zikatero tingoti zikulakwika kuti tikulephera kuwauza It is just unfortunate that we fail to tell him koma sizimayenera zikhale choncho eti? but that is not how things are meant to be right? Chifukwa ikafika nthawi yovala kondomu ija Because, when it comes to the time of wearing the condom imafunika kuvala akatota, eti? is supposed to be worn when one is erect, right?

W: $\quad$ Eee

W: $\quad$ Yes

In example 3 the women outline the 'regulations' they fail to meet, namely the need for husbands to accompany wives to the antenatal clinic (line 14), having an HIV test together (line 2) and (proper) use of condoms (lines 4ff.). In this, the husband is a co-actor within the social structure in which the woman operates (van Leeuwen 2008), yet he affects the woman's agency to act. Here, the women utilise their experiential knowledge as a resource to negotiate the medical knowledge with the heath professional. The women seem to accept the authority of the medical discourse but indicate that there is a tension between practices learned in the clinic and the everyday realities of HIV/AIDS, in particular their sexual practices in the home due to their position in the traditional patriarchal society. Consequently, example 3 demonstrates the relationship between medical knowledge and experiential or local knowledge in this context. In this, HP3 showed a different approach to the other six health professionals featured in the larger study, both in her formatting of questions which actually led to discussions and by opening with a less visible framing of the regulative discourse as there was a lengthy discussion to which the women actually contributed meaningfully.

However, as is also shown later in example 3 and elsewhere in our data, more visible forms of regulative discourse are adopted by HP3. In fact, this health professional also periodically uses strategies that actually reinforce the regulative discourse which characterises the counselling talk, namely when she directs the women to speak 'one at a time' (not shown here); when she selects who should speak by ignoring W3's rhetorical question (line 15); while she appoints another woman to speak, 'what are you saying, yes, you?' (line 17); and bringing that part of the discussion to a close by interrupting W4 (line 19) in order to present her advice on the matter (lines 23ff). By regulating the social order in the talk, who speaks and at what time, the participants are positioned as 'pedagogic subjects.' Within the medical encounter, counter-divisions of 'class' are also created where class acts as a determinant of power which is manifested through the displays of the health professional's knowledgeability against the 'less knowledgeable' clients (Montgomery et al. 2006). Consequently, HP3's strategies reinforce the power differentials between the health professionals 
and the women. In turn, these have the potential to perpetuate the constitutive power inequalities in the home, as the women's agency to freely speak up is not acknowledged.

Towards the end of the discussions in example 3, HP3's talk reverts to a didactic format in which she delivers advice and further information on effective use of a condom (lines 23ff) (i.e., checking the expiry date and ensuring it is properly worn). Delivering information and advising are some of the activities which have also been illustrated in other studies of HIV/AIDS counselling discourse (Silverman 1997). But, based on what the women raise in the example, such information and advice may not be what the women need at this stage. This style of talk reinforces the power differentials between them, and by interrupting the women's concerns with advice she relegates the women to a passive listening position while she adopts the position of knowledgeable expert exerting power over the less powerful (e.g., Montgomery et al. 2006). Rather, what is needed is a redress of the challenges that the women express. Thus, the women's agency as they explore other relevant forms of knowledge (local and experiential) is controlled as the health professionals - HP1 (examples 1 and 2) and HP3 (example 3) - seem to prioritise the unproblematic reproduction of authorised medical knowledge.

\section{Implications and conclusions}

The examples that we have been able to analyse in detail within the scope of this chapter, therefore, reveal two elements in the enactment of regulative discourse in HIV/AIDS counselling talk in rural Malawi, which are more widely supported elsewhere (Chimbwete-Phiri 2019; Chimbwete-Phiri \& Schnurr forthcoming): a tension between authorised medical knowledge and local knowledge about HIV/AIDS and how such a disparity between knowledge types constitutes unequal power relations between the health professionals and the women in this health care context. Through the counselling sessions, the health professionals act as agents of 'symbolic control' (Sarangi \& Roberts 1999: 8); they are involved in relaying the control of higher 'official discourses' while neglecting the local ones of the women. This is similar to what Mulderrig (2017) uncovered in the 'biopedagogic' discourse of obesity: those who have expert knowledge bring a seeming rationality to those who lack it, giving them the information to be rational, while occluding the social relations and the context with which it is associated.

Nevertheless, these counselling sessions remain an important forum for education and empowerment. The interaction of health practitioners and patients in Malawi has demonstrated that there is a potential for discussion and inclusion of local and experiential knowledge if the health professionals attend to some of the linguistic and discoursal features of their talk as presented in our analysis. As has been argued elsewhere, it is not information about prevention 
and treatment of HIV/AIDS that people lack in Malawi and southern Africa more generally, but lack of compliance with that knowledge (Chasi \& de Wet 2006; Penn et al. 2011). Moreover, others have argued that health education is not the only necessary step to curb health problems and provide access to treatment (Montgomery et al. 2006). The health professionals in the examples aim to empower their women clients, but at the same time they use strategies that reproduce existing inequalities by not giving the women the chance to explore the issues. Consequently, subjectivities are constructed through the regulative nature of the counselling discourse as the health professionals seem to focus on ensuring that the women are compliant, rather than engaging in a discussion of why the women fail to be compliant.

The health professionals, in the examples in our analysis, emphasise giving the women the information by checking what should be done. This is similar to what others have dubbed 'responsibilisation' in neo-liberal health provision (e.g. Barry et al. 1996), which has been criticised as reducing the patients to 'subjects' without considering the material aspects of their lives. Within this medical pedagogy the role of the women needs to be upheld by giving them space to assert themselves because the counselling sessions are a forum where theory meets practice (after Freire 1970). Furthermore, the interaction has to enhance the agency of the women to engage with their own local and experiential knowledge in the interaction as they express ways of dealing with the challenges they face. The link between action and personal experience are vital in this 'responsibilisation' discourse (Colvin et al. 2010).

However, our analysis has also revealed that the subject positions of participants, and the power relations between them and the health professionals in this context, vary depending on the different health professionals holding the counselling sessions. From what is seen in the interactional data, more interactive sessions are possible and more experiential knowledge can be shared if the health professionals realise the significance of certain linguistic and discoursal strategies that they employ. While the micro level of the interaction can be addressed by focusing on improving their style (i.e., by devising ways of holding more discussions and evaluating the sessions with the health professionals) (e.g., Silverman 1997), the macro-level structural relations realised in the talk are more complicated and less amenable to immediate intervention. These macro-level relations entail not only, in the context of this study, deep-seated patriarchal relations which exist within the family, but also in all societies an asymmetrical structural distribution which determines who has the power to access transformative forms of knowledge, or the 'unthinkable' (Bernstein 2000: 43). To counter these asymmetrical relations, a transformative medical pedagogy should aim at shaping the entire person's thinking and enabling them to think of their own situation through a process of 'conscientisation' (Freire 1970). This is a move towards a 'critical pedagogy' (Freire 1970) of health education, through which the women are given the floor to work it out for themselves in order to change their lives. To achieve this, we propose 
granting the women more space and time for discussions to allow a gradual conscientisation where critical consciousness is raised in order for women to become empowered practically. If they do not have the power to 'own' the knowledge in the counselling sessions, their capacity to go home, engage their sexual partners and talk through with them on sexual practices, condom use, and disclosing HIV status, as recommended in the sessions, will remain hard to achieve.

In conclusion, applied linguistics studies such as this have the potential to explore in detail the strengths and weaknesses of life-saving health information such as for HIV/AIDS counselling sessions, even in 'diverse' contexts such as rural Malawi, and enhance the lives of HIV-positive citizens in tangible ways. It is not just engaging the clients in the counselling talk that is vital, but through the 'application' of a contextualised analysis of language and discourse, we can detail the strengths and weaknesses of the talk, creating an evidence base which will inform transformative forms of engagement that can be realised in the clients' everyday practices.

\section{References}

Barry, A., Osborne, T. and Rose, N. (eds) 1996 Foucault and practical reason: Liberalism, neo-liberalism and rationalities of government. London: University College London.

Bernstein, B. 1990 Class, codes and control, Vol. 4: The structuring of pedagogic discourse. London: Routledge.

Bernstein, B. 1996 Pedagogy, symbolic control and identity: Theory, research, critique. London: Taylor \& Francis.

Bernstein, B. 2000 Pedagogy, symbolic control and identity: Theory, research, critique. Revised ed. Lanham, MD: Rowman and Littlefield Publishers.

Buzzelli, C. and Johnston, B. 2001 Authority, power, and morality in classroom discourse. Teaching and Teacher Education, 17(8): 873-884.

Chasi, C. and de Wet, G. 2006 Communication, choice and freedom with reference to risk in aspects of communication on HIV/AIDS. South African Journal for Communication Theory and Research, 32(1): 119-136.

Chimbwete-Phiri, R. 2019 The reproduction and negotiation of knowledge in HIV/AIDS consultations in Malawi. Unpublished doctoral dissertation, University of Warwick.

Chimbwete-Phiri, R. and Schnurr, S. (forthcoming). Improving HIV/AIDS consultations in Malawi: How interactional sociolinguistics can contribute. In Demjén, Z. (ed.), Contemporary applied linguistics in illness and healthcare contexts. London: Bloomsbury.

Colvin, C.J.S. Robins and Leavens, J. 2010 Grounding 'responsibilisation talk': Masculinities, citizenship and HIV in Cape Town, South Africa. The Journal of Development Studies, 46(7): 1179-1195. 
Finn, M. and Sarangi, S. 2010 Articulation of knowing: NGOs and HIV-positive health in India. In Higgins, C. and Norton, B. (eds), Language and HIV/ AIDS. Bristol: Multilingual Matters. pp. 233-249.

Freire, P. 1970 Pedagogy of the oppressed. M.B. Ramos trans. New York: Continuum.

Haas, A.D., Msukwa, M.T., Egger, M., Tenthani, L., Tweya, H., Jahn, A., Gadabu, O.J., Tal, K., Salazar-Vizcaya, L., Estill, J., Spoerri, A., Chimbwandira, F., Egger, M. and Keiser, O. 2016 Adherence to antiretroviral therapy during and after pregnancy: Cohort study on women receiving care in Malawi's Option B+ program. Clinical Infectious Diseases: An Official Publication of the Infectious Diseases Society of America, 63(9): 1227-1235.

Higgins, C. and Norton, B. (eds) 2010 Language and HIV/AIDS. Bristol: Multilingual Matters.

Hult H, Lindblad, F.M., Lindh, F.A., and Thörne, K. 2009 Pedagogical processes in healthcare: An exploratory study of pedagogic work with patients and next of kin, Education for Health, 22(3).

Keehn, E. and Karfakis, J. 2014 Current practices to increase uptake, retention and adherence for Option B+ in Malawi. Lilongwe: mothers2mothers Malawi.

Kreps, G.L. 2012 Translating health communication research into practice: The importance of implementing and sustaining evidence-based health communication interventions. Atlantic Journal of Communication, 20(1): 5-15.

Love, K. 2000 The regulation of argumentative reasoning in pedagogic discourse. Discourse Studies, 2(4): 420-451.

Lupton, D. 1992 Discourse analysis: A new methodology for understanding the ideologies of health and illness. Australian Journal of Public Health, 16(2): 145-150.

MacDonald, M.N. 2002 Pedagogy, pathology and ideology: The production, transmission and reproduction of medical discourse. Discourse and Society, 13(4): 447-467.

MacDonald, M.N., Badger, R.G. and Regan, J.P. 2009 The social cognition of medical knowledge: With special reference to childhood epilepsy. Critical Inquiry in Language Studies, 6(3): 176-204

Montgomery, C.M., Mwengee, W., Kong'ong', M. and Pool, R. 2006 'To help them is to educate them': Power and pedagogy in the prevention and treatment of malaria in Tanzania. Tropical Medicine \& International Health, 11(11): 1661-1669.

Moore, A. 2005 Modelling agency in HIV treatment decision-making. Australian Review of Applied Linguistics, 19: 103-122.

Mulderrig, J. 2017 The language of 'nudge' in health policy: Pre-empting working class obesity through 'biopedagogy'. Critical Policy Studies. DOI: https:// doi.org/10.1080/19460171.2017.1398672

Penn, C., Watermeyer, J. \& Evans, M. 2011 Why don't patients take drugs? The role of communication in patient adherence and work of the pharmacist in HIV/AIDS. Patient Education Counselling, 83: 310-318. 
PEPFAR 2017 Malawi country operational plan 2017: Strategic direction summary. Available online: http://www.pepfar.gov [Last accessed November 2017.

Sanderson, T. and Angouri, J. 2013 'I'm an expert in me and I know what I can cope with': Patient expertise in rheumatoid arthritis. Communication \& Medicine, 10(3): 249-261.

Sarangi, S. and Roberts, C. (eds) 1999 Talk, work and institutional order: Discourse in medical, mediation and management setting. Berlin: Mouton de Gruyter.

Silverman, D. 1997 Discourses of counselling: HIV counselling as social interaction. London: SAGE Publications.

Sinclair, J. and Coulthard, R.M. 1975 Toward an analysis of discourse. Oxford: Oxford University Press.

Stivers, T. 2006 Treatment decisions: Negotiations between doctors and parents in acute care encounters. In Heritage, J. and Maynard, D. (eds), Communication in medical care: Interaction between primary care physicians and patients. Cambridge: Cambridge University Press. pp. 279-312.

Tenthani, L., Haas, A.D., Tweya, H., Jahn, A., van Oosterhout, J.J., Chimbwandira, F., Chirwa, Z., Ng’ambi, W., Bakali, A., Phiri, S. and Myer, L. 2014 Retention in care under universal antiretroviral therapy for HIV infected pregnant and breastfeeding women ('Option B+') in Malawi. AIDS (London, England), 28(4): 589-598.

van Dijk, T.A. 2002 Discourse, knowledge and ideology. Paper for the International LAUD Symposium on Language and Ideology. Landau, 25-28 March.

van Leeuwen, T. 2008 Discourse and practice: New tools for critical discourse analysis. Oxford: Oxford University Press.

Vickers, C.H., Goble, R. and Lindfelt, C. 2012 Narrative co-construction in the medical consultation: How agency and control affect the diagnosis. Communication \& Medicine, 9(2): 159-171.

Waitzkin, H. 1991 The politics of the medical encounters: How patients and doctors deal with social problems. London: Yale University Press.

Walsh, S. 2011 Exploring classroom discourse: Language in action. Abingdon, Oxon: Routledge.

\section{Appendix A: Transcription key}

(.) a regular pause or gap of less than a second.

(n) number in parenthesis indicates a pause in speakers' talk of more than a second.

:: $\quad$ stretched or prolonged sounds, the length of the row of colons represents the prolongation of the sound.

(( )) descriptions and comments by author.

? indicates a rising intonation 


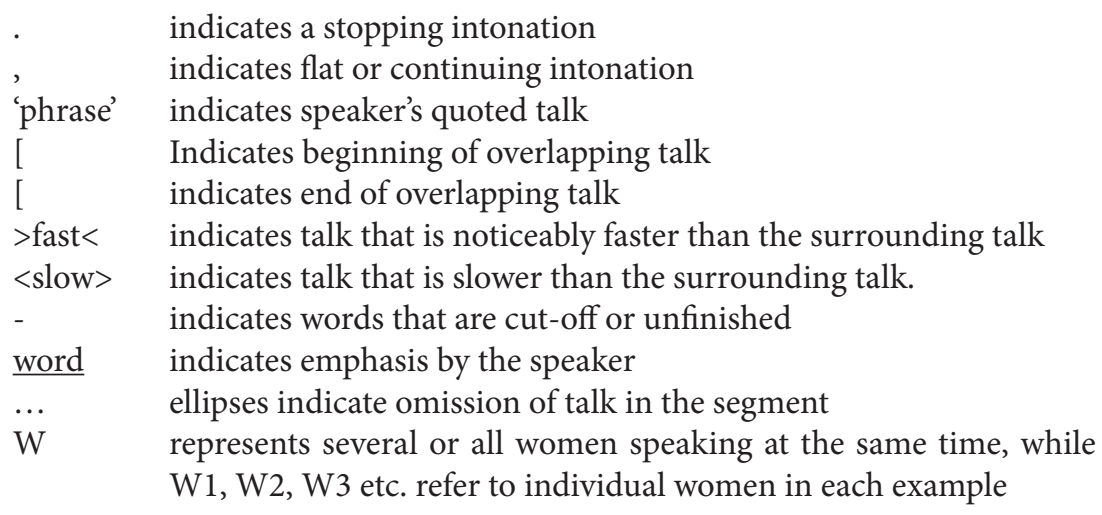

